\title{
VIVENCIANDO UMA PROPOSTA EMANCIPATÓRIA NO ENSINO DE SEMIOLOGIA PARA A ENFERMAGEM
}

\author{
Maria Socorro de Araújo Dias ${ }^{1}$ \\ Maria de Fátima Antero Sousa Machado \\ Raimunda Magalhães da Silva ${ }^{3}$ \\ Ana Karina Bezerra Pinheiro ${ }^{4}$
}

Dias MSA, Machado MFAS, Silva RM, Pinheiro AKB. Vivenciando uma proposta emancipatória no ensino de semiologia para a enfermagem. Rev Latino-am Enfermagem 2003 maio-junho; 11(3):364-70.

Objetivou-se analisar o ensino de Semiologia através dos programas das disciplinas das cinco universidades do Estado do Ceará, especificamente de uma universidade pública. Observaram-se três aulas e realizaram-se reuniões com docentes e discentes, a fim de levantar dados sobre o processo ensino-aprendizagem. As docentes apresentaram experiência no ensino e pesquisa, e reconheceram que o elevado número de alunos prejudica o ensino-aprendizagem. Os discentes referiram dificuldades na elaboração de diagnóstico de enfermagem e no contato inicial com cliente hospitalizado, ocasionando insegurança e rejeição à prática da disciplina.

DESCRITORES: ensino, aprendizagem, enfermagem

\section{EXPERIENCING AN EMANCIPATORY PROPOSAL IN THE TEACHING OF SEMIOLOGY TO NURSING}

The aim was to analyze the teaching of Semiology through the programs of subject matters at five universities in the State of Ceará and, specifically, that of a public university. Three (3) classes were observed and meetings were held with teachers and students for collecting data about the teaching-learning process. The teachers presented teaching and research experience, and acknowledge that the high number of students impairs teaching-learning. The students mentioned difficulties in the elaboration of the nursing diagnosis and in the initial contact with the hospitalized client, causing insecurity and rejection of the practical part of the subject matter.

DESCRIPTORS: teaching, learning, nursing

\section{VIVENCIANDO UNA PROPUESTA EMANCIPATORIA EN LA ENSEÑANZA DE SEMIOLOGÍA EN ENFERMERÍA}

El objetivo es el análisis de la enseñanza de la semiología a través de los programas de estudio de la disciplina en cinco universidades estatales y el análisis de una universidad publica. Se observaron tres grupos y se realizaron reuniones con docentes y estudiantes con el fin de recolectar los datos sobre el proceso de enseñanza aprendizaje. Los maestros introducen la experiencia en la enseñanza y en la investigación y reconocieron que el elevado numero de estudiantes, perjudica el proceso enseñanza-aprendizaje. Los estudiantes refieren dificultades en la elaboración del diagnostico de enfermería y en el contacto inicial con el cliente hospitalizado, ocasionando inseguridad y rechazo a la práctica de la disciplina.

DESCRIPTORES: enseñanza, aprendizaje, enfermería

\footnotetext{
${ }^{1}$ Enfermeira, Mestranda da Universidade Federal do Ceará, Professor do Curso de Enfermagem da Universidade Estadual Vale do Acaraú;

${ }^{2}$ Enfermeira, Mestranda da Universidade Federal do Ceará, Professor de Enfermagem da Universidade Regional do Cariri, endereço: Rua: Catão Mamede, 929 - Ap. 202 - Aldeota - 60140-110 - Fortaleza - Ceará - Brasil; ${ }^{3}$ Enfermeira Doutora, Professor; ${ }^{4}$ Enfermeira Mestre, Professor Assistente. Universidade Federal do Ceará
} 
$\boldsymbol{A}$ humanidade tem acumulado, através dos séculos, uma gama de conhecimentos, possibilitando progresso técnico-científico. Atualmente, acredita-se que essa evolução ocorra quando há reflexão crítica sobre o passado e flexibilidade para mudanças.

Nesse contexto, em 1994, houve reestruturação curricular no curso de enfermagem, proposta pela Portaria 1721, sendo inserida a obrigatoriedade do conteúdo de Semiologia e Semiotécnica, com flexibilidade na forma de abordagem, podendo ser uma disciplina específica ou conteúdo integrante de outra.

Sentiu-se, de princípio, a necessidade de avaliar essa disciplina, haja vista acreditar-se que a compreensão e obtenção de qualidade, passam por esse processo. Avaliação é conceituada como: "Processo intencional, auxiliado por diversas ciências e que se aplica a qualquer prática"(1). Acrescente-se, ainda, que a avaliação é processual, necessitando de planejamento e estabelecimento de objetivos, podendo ser definida como questão política.

Por compreender a relevância da avaliação para o aprimoramento das atividades e atendendo a um prérequisito da disciplina Estudo Crítico dos Programas de Enfermagem, do Curso de Mestrado, é que a análise da disciplina de Semiologia demonstrou o quanto de importância acumula.

Para a sua realização, selecionou-se a avaliação emancipatória, caracterizada por um processo de descrição, análise e crítica de uma determinada realidade, com o objetivo de posterior transformação. O compromisso principal dessa avaliação é com a realização de autocrítica pelos sujeitos envolvidos, para gerenciamento de suas próprias alternativas de ação.

Os marcos conceituais envolvidos na avaliação emancipatória são a emancipação, que requer consciência crítica, a decisão democrática, implicando em envolvimento responsável e compartilhado, a transformação, que está relacionada às alterações geradas coletivamente, e a crítica educativa, que diz respeito à proposta oferecida por participantes do processo ${ }^{(2)}$.

Nesse estudo, portanto, a avaliação emancipatória enfatiza a participação do aluno na situação do ensinoaprendizagem e reconhece a troca de experiência entre professor e aluno, usando abordagem crítica e construtiva.
Avaliar criticamente a disciplina de Semiologia ministrada em um curso de enfermagem.

\section{METODOLOGIA}

O estudo é de natureza qualitativa, do tipo descritivo. Os aspectos éticos foram respeitados, conforme Parecer 196/96 que regulamenta normas de pesquisas envolvendo seres humanos. Houve contato formal com as três professoras da disciplina de Semiologia do curso de Enfermagem de uma universidade pública do Estado do Ceará, sendo solicitada autorização para realização do trabalho, e feito convite para participação no processo de avaliação. Após a autorização, traçou-se o planejamento.

A coleta de dados se deu em dois momentos descritos a seguir.

- Descrição da realidade

A primeira etapa constituiu-se da preparação da investigação, observação e descrição da realidade.

Para compreender os diferentes contextos do ensino de Semiologia em Enfermagem, no Ceará, inicialmente investigou-se os programas da disciplina nos cursos das cinco universidades cearenses. Os dados referentes ao conteúdo programático, objetivos, números e titulação dos professores, carga horária, semestre no qual a disciplina é desenvolvida e referências bibliográficas foram objetos de investigação e comparação para avaliação da disciplina na universidade proposta.

Posteriormente, em um encontro com as professoras, foi discutida a evolução do trabalho, tendo, oportunamente, sido solicitado depoimento das mesmas, por escrito, sobre a disciplina.

Em seguida, foi elaborada oficina de avaliação da disciplina realizada com os alunos, convidados então a participar, como voluntários. O local selecionado para desenvolver essa atividade foi o Departamento de Enfermagem. A programação traçada contemplou três etapas desenvolvidas aproximadamente em três horas (relaxamento, depoimentos sobre a disciplina e autoavaliação do desempenho na disciplina). Apesar de quinze alunos terem manifestado desejo de participar da oficina, somente três compareceram.

- Crítica da realidade

Esta fase caracteriza-se, essencialmente, pela 
tomada de consciência e discussão de desajustes e contradições que eventualmente existam no programa. É momento que envolve procedimentos entre alunos e professores da disciplina ${ }^{(2)}$.

Nesse momento, foram sistematizados os dados obtidos através da comparação do programa da disciplina com aqueles das outras universidades, da oficina com os alunos e depoimentos das docentes. Primeiramente, foram apresentados os dados referentes ao ensino de Semiologia para a Enfermagem no Ceará e, posteriormente, avaliada criticamente a disciplina na Universidade Federal do Ceará.

\section{APRESENTAÇÃO E DISCUSSÃO DOS RESULTADOS}

O Ensino de Semiologia nos Cursos de Enfermagem no Ceará

Do que foi observado na integralização curricular dos cursos investigados, permite-se dizer que não há padronização na denominação da disciplina em estudo, nos cursos de graduação em Enfermagem. Em quatro deles, foram utilizados os termos: Semiologia e Semiotécnica, enquanto na universidade avaliada, foi denominada, simplesmente, de Semiologia.

Por sua vez, foi também encontrada divergência quanto ao número de créditos ofertados nos diversos cursos e percebeu-se que a disciplina de Semiologia é contemplada com 06 créditos; entretanto, nos cursos que propõem estudar Semiologia e Semiotécnica, concomitantemente, ocorreu variação em números de créditos de 06,08 e 12. Salientamos que um crédito equivale a 15 horas-aulas.

O desenvolvimento da disciplina, em dois cursos, acontece no quarto semestre e nos demais têm ocorrência no $3^{\circ}$ e $5^{\circ}$ períodos. Os dados obtidos demonstraram variação significativa quanto ao número de docentes, variando de 02 a 07. No que diz respeito à sua titulação, há variação no número de especialistas, mestres e doutores.

Em todos os cursos foi observada congruência do objetivo proposto, com otimização de preparação do discente para o cuidar em enfermagem. O objetivo, em referência, guarda íntima relação com o conteúdo programático proposto.
A análise da metodologia utilizada, para o desenvolvimento do conteúdo programático, deu vez ao conhecimento de uma diversificação de métodos e técnicas, superando o modelo tradicional de ensino, no qual há relação verticalizada entre professor e aluno. Como exemplos, observamos os seminários, dinâmicas de grupo, aulas participativas, estudos individuais e grupais e aulas expositivas.

O uso de estratégias de ensino não convencionais propiciam maior assimilação e análise do conteúdo estudado. Por outro lado, o ensino centrado na figura do professor, que detém a autonomia do conhecimento, usando estratégias repetitivas, com aulas expositivas, fluxo unilateral de comunicação dificulta o desenvolvimento do pensamento crítico do aluno ${ }^{(3)}$.

Dentre os métodos, técnicas e abordagens utilizados, não há porque discordar de quando afirmam que a abordagem sociocultural ou problematizadora ultrapassa a premissa de que os alunos nada sabem, partindo do princípio de que toda realidade precisa ser transformada. A valorização da ação grupal leva o homem a se perceber como sujeito da própria educação, capaz de agir e refletir sobre suas ações ${ }^{(4)}$.

Tal modelo tem reflexo também nos mecanismos de avaliação que ocorrem de forma processual, através de estudos grupais e individuais, diário de campo, registro de expectativas, devolução de técnicas em laboratório, avaliação progressiva e estágios supervisionados.

No que tange à bibliografia embasadora da disciplina, percebeu-se, nos vários cursos, preocupação por mantê-la atualizada, embora tenha sido sentida escassez de bibliografia específica da Enfermagem. O fato deve estar relacionado com a carência de produção científica na área.

Analisando o Ensino de Semiologia em uma Universidade Pública de Fortaleza

O conteúdo de Semiologia foi iniciado desde a fundação do curso em 1976, embora ministrada na disciplina de Fundamentos de Enfermagem.

Em 1997, com a reforma curricular, o conteúdo passou a ser ministrado na disciplina Semiologia, com a carga horária de 90h/aula teórico-prática, e ministrada por três professoras, sendo uma com doutorado e duas com mestrado. 
A partir dos depoimentos das docentes sobre suas experiências na área, relevância do conteúdo da disciplina para a enfermagem e dificuldades enfrentadas na disciplina, iniciou-se a crítica da realidade.

A etapa de crítica do material caracteriza-se pelo recuo do próprio grupo avaliado, através de procedimentos de reflexão sobre sua prática ${ }^{(2)}$. Sendo assim, essa etapa efetiva-se, basicamente, pela tomada de consciência do grupo, acerca das dificuldades e barreiras reais ou potenciais que obstaculizam a consecução do ideal.

De tal sorte, com a participação efetiva das professoras, foi-se seguindo o paradigma da avaliação emancipatória que preconiza o avaliador como participante envolvido durante todo processo avaliativo, por conhecer, mais profundamente, a problemática estudada.

Vivência Profissional das docentes em Semiologia

Percebeu-se um vasto caminho já percorrido pelas professoras da disciplina, nas áreas de pesquisa, ensino e assistência.

Em relação ao ensino, todas lecionaram a disciplina Fundamentos de Enfermagem, o que thes assegurou experiência para o ensino de Semiologia. Atualmente, as docentes ministram cursos para outras docentes e para o pessoal de serviço, além de desenvolverem pesquisas enfatizando a aplicação da Semiologia.

A respeito da relação quantitativa professor-aluno, as docentes entrevistadas foram unânimes em referir que a relação não é a ideal, haja vista a turma em estudo ser composta por 45 alunos para acompanhamento de apenas três professoras, nas atividades teórico-práticas, enquanto o almejado seria seis discentes para cada docente.

Verificou-se a problemática levantada pelas docentes quanto ao número de alunos, prejudicando a participação desses nas discussões em sala de aula.

O grande número de alunos para cada professor pode influenciar sobre o tipo de comunicação existente. É indiscutível a importância da interação e comunicação entre os sujeitos participantes do processo educativo ${ }^{(4)}$. Provavelmente, uma turma com grande número de alunos dificulta o desenvolvimento de pedagogia problematizadora, uma vez que o diálogo se torna mais raro, repercutindo negativamente sobre os processos de reflexão e de humanização.
A carga horária teórico-prática foi considerada por todas as docentes como insuficiente para atingir os objetivos propostos pela disciplina. A carga horária de seis créditos é a menor, se comparada aos demais cursos do Ceará. Portanto, há o desejo pelas professoras de incrementar outras estratégias que facilitem o ensinoaprendizagem.

A Semiologia constitui o cerne do curso, caracterizando-se como momento ímpar de construção de uma teoria/prática capaz de preparar os enfermeiros para o cuidado humanístico ${ }^{(5)}$.

Outra preocupação apontada por uma docente foi a dificuldade alusiva à continuidade do conteúdo em outras disciplinas que compõem a grade curricular.

Essa desarticulação deveria ser totalmente anulada, visto que a implementação de cuidados de enfermagem depende diretamente da realização de entrevista e exame físico bem elaborados, como também do estabelecimento preciso de diagnósticos de enfermagem.

Foi referido por uma das professoras o fato de, na prática, não se encontrar enfermeiro desenvolvendo procedimentos de semiologia, o que de certa forma torna o conteúdo ensinado na disciplina uma ação no nível teórico, com importância reduzida na prática de enfermagem.

O conteúdo, no que se refere ao diagnóstico de enfermagem, foi caracterizado como o mais difícil para realizar a articulação entre teoria e prática. Assim, é importante a reflexão sobre o ensino de diagnósticos de enfermagem, pois se o seu uso envolver somente um mero exercício intelectual, descontextualizado e sem a participação dos enfermeiros, o diagnóstico de enfermagem tornar-se-á apenas um "elefante branco" na profissão ${ }^{(6)}$.

No que diz respeito à bibliografia da disciplina, uma das docentes caracterizou como insuficiente o acervo da biblioteca para o número de alunos, considerando que algumas referências são comuns ao curso de enfermagem, medicina, farmácia e odontologia. Referiu ainda que a literatura relacionada especificamente à Semiologia em enfermagem, publicada em livros e periódicos, não é tão vasta e, muitas vezes, não se encontra disponível na biblioteca.

Observa-se, portanto, a dificuldade de alguns discentes no aprofundamento do conteúdo ministrado, 
dada a dificuldade, principalmente, em acessar fontes bibliográficas recentes e adequadas. Há busca constante para o desenvolvimento tecnológico, o que não vem, no entanto, sendo acompanhada pela universidade brasileira $^{(7)}$.

Observou-se, contudo, que a relevância da disciplina para o curso de enfermagem foi ressaltada por todas as docentes envolvidas e referida, ainda, como suporte para a assistência de enfermagem abordada em disciplinas posteriores.

Ressalte-se que, durante as aulas, foi observado o relacionamento aluno-professor e professor-aluno considerado amigável, carinhoso, incentivador e confiável. No entanto, observou-se uma situação enfrentada por uma discente, no momento em que necessitou de se expressar para os demais colegas e parecia que suas idéias se encontravam bloqueadas, muito embora a acadêmica tivesse participado ativamente das discussões grupais. Nesse instante, sentiu-se a ausência do professor incentivador, capaz de estimular a aluna a superar as dificuldades e valorizar seu potencial, mesmo sendo esse um caso isolado. A auto-avaliação do professor, a criatividade, o preparo didático e a motivação à mudança são critérios primordiais para que se tenha o processo ensino-aprendizagem de qualidade ${ }^{(8)}$.

Para tanto, o docente deve buscar novas estratégias de ensino que despertem a consciência crítica no aluno, privilegiando situações de aprendizagem e que possibilitem atitudes criativas, criticas e transformadoras ${ }^{(3)}$.

Vivência dos discentes na disciplina Semiologia

Para analisar a participação dos discentes e sua avaliação da disciplina, realizou-se uma dinâmica com o objetivo de analisar os sentimentos dos alunos, sobre a disciplina. Para tanto, foram colocadas diversas figuras no chão, para que os participantes escolhessem uma gravura que representasse o seu sentimento a partir da pergunta norteadora: como você se percebe na disciplina de Semiologia?

Uma aluna que selecionou a figura de um abacaxi, fez o seguinte relato:

Não entra diagnóstico na minha cabeça. Acho um abacaxi que tenho que descascar e não estou conseguindo... É um amontoado de coisas e não consigo aprender.

Observou-se, através dessa fala e do discurso de outros alunos, que a maior preocupação dos mesmos com relação ao conteúdo da disciplina é como estabelecer diagnósticos de enfermagem precisos. Associa-se essa dificuldade ao fato de que, para o aluno, elaborar um diagnóstico de enfermagem, é necessário que esteja capacitado a reconhecer dados objetivos e subjetivos através do desenvolvimento de instrumentos adequados para adquirir essa habilidade.

Para formular diagnósticos, é exigido conhecimento nas áreas biológicas, psicológicas, humanas e, ainda, de fisiopatologia ${ }^{(9)}$. Percebemos que este corpo de conhecimentos deve estar articulado logicamente para que possa representar significado para a enfermagem. Provavelmente, os discentes não são esclarecidos quanto à relevância das disciplinas básicas para a profissão e, quando são estimulados em Semiologia, para desenvolver um senso crítico e raciocínio reflexivo, tendo como requisito básico o domínio do conteúdo dessas disciplinas, sentem-se despreparados.

Para tanto é imprescindível o impulso à criatividade e ao conhecimento crítico do estudante em seu potencial individual e coletivo como busca incansável para transformação e desenvolvimento próprio ${ }^{(10)}$.

Outra dificuldade apontada pelos alunos foi 0 primeiro contato com um cliente hospitalizado. Observouse que, apesar de ser uma experiência ansiosamente aguardada pelos acadêmicos, pode ser chocante em um primeiro momento. Esse fato foi explicitado nas seguintes falas:

Sinto-me uma árvore que vai dar bons frutos. Como esta árvore, sinto-me em constante crescimento... Agora, o que me deixou preocupada, foi a segunda prática no hospital; a turma toda sentiuse mal... Aquele homem com um negócio no pescoço... eu não sabia direito o que fazer, como fazer.

O primeiro momento, no hospital, foi horrível; eu até sabia o que e como fazer, entretanto, psicologicamente, não aceitava $o$ contato com o cliente, tanto é que eu dizia e uma colega fazia. Mas acho que o problema estava em mim.

O impacto do ambiente hospitalar pode ocasionar, em alguns discentes, sentimentos de insegurança e até mesmo de rejeição ao desenvolvimento de atividades práticas da disciplina.

Essa mesma experiência foi detectada em outro 
estudo, fazendo referência aos estudantes de enfermagem inseguros durante as primeiras atividades práticas ${ }^{(7)}$. Ocorre que as vulnerabilidades pessoais muitas vezes não são compartilhadas com os docentes por falta de confiança, relações superficiais ou medo de repreensão.

Ainda, na primeira dinâmica, foi observado que os acadêmicos reconhecem a importância da disciplina, tendo também sido relatado que existem barreiras relacionadas à dificuldade de conciliar múltiplos papéis. Todas as alunas participantes da oficina são bolsistas, cursam as disciplinas do terceiro semestre de enfermagem, tendo uma alta carga horária a cumprir, dentro da Universidade.

Em um segundo momento da oficina, foi realizada uma dinâmica utilizando sinais de trânsito. Nessa fase, foi dada aos participantes a oportunidade de escolher uma gravura de sinal de trânsito que representasse o desenvolvimento da disciplina, sendo os mesmos também encorajados a emitir uma avaliação sobre essa figura.

Uma acadêmica selecionou a gravura de uma lombada e justificou:

O carrinho anda, anda e de repente pára, reduz a marcha, é uma lombada, e esta serve como sinal de alerta... Vou parar, estudar, aprender, desenvolver, crescer e futuramente aplicar a melhor intervenção que eu puder....

Percebeu-se através desse relato, que a discente se auto-avaliou durante o desenvolvimento da disciplina. As dificuldades enfrentadas funcionam como estímulo para reflexão e aprofundamento dos conhecimentos.

Acredita-se no crescimento da discente que se auto-avalia continuamente, em razão da compreensão que se tem da avaliação, como um processo que a todo momento deve ser analisado (avaliado) e (re)estruturado ${ }^{(1)}$.

Outra estudante explicitou a relevância da disciplina, selecionando o sinal que representa a mão dupla:

Semiologia na Enfermagem direciona para a maneira adequada do cuidar, resgatando, muitas vezes, o passado do paciente, a história dele, não sendo somente um exame físico.

Observa-se que essa acadêmica apreendeu a importância da disciplina para a profissão, além de perceber o elo de ligação entre a mesma e as demais a serem cursadas. O levantamento de dados e estabelecimento de diagnósticos de enfermagem são, para a aluna, um ponto de apoio para a determinação de resultados e das intervenções de enfermagem.

Verificou-se, assim, através da oficina, que os estudantes de enfermagem, ao cursarem Semiologia, percebem sua magnitude e a necessidade do conteúdo ser compartilhado por todos os docentes do curso, para aprofundamento em outras disciplinas, em um nível crescente de complexidade.

\section{CONSIDERAÇÕES FINAIS}

A avaliação da disciplina de Semiologia permitiu um contato, embora superficial, com o planejamento dessa disciplina nos diversos cursos de graduação em Enfermagem no Estado do Ceará. O contato mais intenso com a disciplina deu-se no processo de avaliação dessa no curso de uma universidade pública de Fortaleza.

A opção por Semiologia pode ser compreendida como desafiadora pela própria inovação, enquanto disciplina. Acredita-se, no entanto, que todo planejamento necessita de avaliação contínua e com maior intensidade, no processo de implantação.

Faz-se necessário ressaltar o apoio irrestrito das docentes da disciplina, visto como facilitador neste caminhar.

A metodologia emancipatória gera transformação social do saber, constitui método pedagógico da libertação, criticidade, participação e conscientização no aluno e professor $^{(11)}$.

Diante dos dados coletados e discutidos, são apresentadas, a seguir, algumas sugestões, a título de contribuição para um melhor desenvolvimento da disciplina, uma vez compreendida a importância deste conteúdo para uma prática de Enfermagem com qualidade:

- integrar o conteúdo de Semiologia nas atividades práticas das demais disciplinas, em níveis crescentes de complexidade;

- melhor planejamento do Departamento de Enfermagem, quanto ao número de docentes da disciplina, para viabilização das práticas a serem executadas;

- solicitar, através da administração superior da Universidade, a aquisição de acervo bibliográfico, de modo a atender à procura por títulos de interesse, segundo suas especificidades;

- que o conteúdo teórico e prático sejam ministrados concomitantemente, para adequar o conhecimento à carga horária existente;

- oportunidade para o aluno desenvolver o pensamento crítico no contexto real das situações. 


\section{REFERÊNCIAS BIBLIOGRÁFICAS}

1. Demo P. Avaliação sob o olhar propedêutico. Campinas (SP): Papirus; 1996.

2. Saul AM. Avaliação emancipatória: desafio à teoria e à prática de avaliação e reformulação de currículo. $3^{\underline{a}}$ ed. São Paulo (SP): Cortez; 1994.

3. Stacciarini JMR, Esperidião E. Repensando estratégias de ensino no processo de enfermagem. Rev Latino-am Enfermagem 1999; 7(5):59-66.

4. Rozendo CA, Martins EA, Collete N. Comunicação professor-aluno através da pedagogia problematizadora. Rev Bras Enfermagem 1995; 48(1):33-8.

5. Garcia AAMG de S, Silveira MF de A. Um caminho de liberdade: a experiência da disciplina semiologia e semiotécnica. Rev Bras Enfermagem 1998; 51(2):231-44.

6. Cruz D de ALM. Diagnóstico de enfermagem: aspectos históricos e definição. Rev Paul Enfermagem 1994; 13(1/3):37.

7. Pinheiro AKB, Ximenes LB, Varela ZMV. A experiência de ensino em enfermagem utilizando uma pedagogia sóciocultural. In: Silva RM, Barroso MGT, Varela ZMV. Ensino na universidade: integrando graduação e pós-graduação. Fortaleza: Pós-Graduação - DENF/UFC/FFOE/FCPP; 2000. p. 59-68.

8. Freire P. Pedagogia do oprimido. $20^{a}$ ed. Rio de Janeiro (RJ): Paz e Terra; 1992.

9. Araújo TL. de, Guedes MVC. Diagnóstico de enfermagem: Qual a abordagem no novo currículo? In: Araújo TL. de, Guedes, MVC. O uso do diagnóstico na prática de enfermagem. $2^{\underline{a}}$ ed. Brasília: Associação Brasileira de Enfermagem; 1997.

10. Camacho ACLF, Santos FH do E. Refletindo sobre o cuidar e o ensinar na enfermagem. Rev Latino-am Enfermagem 2001; 9(1):13-7.

11. Santos ZM de AS, Silva RM da. Processo ensinoaprendizagem: avaliação numa abordagem transformadora.

Rev Gestão em Saúde 2002; 5(1):63-9. 